\title{
Effects of a group-based exercise program on muscle strength and postural control among community-dwelling elderly women: a randomized-controlled trial
}

\author{
Efeitos de um programa de exercícios em grupo sobre a força muscular e controle postural \\ entre mulheres idosas da comunidade: um estudo randomizado controlado
}

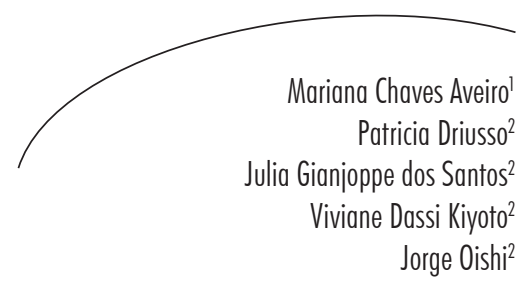

Abstract

Objectives: Verify if a group-based low intensity exercise training program could significantly improve physical variables related to muscle strength and postural control among community-dwelling elderly women. Methods: This study was a non-blinded randomized-controlled trial. Thirty-seven women were allocated according a computer generated randomization list in two groups: Control ( $\mathrm{n}=18$; mean age 68.9(5.7)) and Exercise ( $n=19$; mean age 67.8(4.9)). Main outcome measures were body sway during quiet stance, and knee and ankle isometric peak torque and isokinetic peak torque, power and time acceleration. Exercise group performed a group-based training program on two days per week for 12 weeks. Each training session consisted of stretching exercises, ankle and knee muscle strengthening and balance training. Control group did not undergo any training. Results: Control group did not present significant differences for variables analyzed. Effect size to peak torque and power for non-dominant knee flexors at $60^{\circ} \mathrm{s}$ ( 0.85 and 0.8 , respectively), peak torque and power for non-dominant knee flexors and time acceleration for non-dominant knee extensors at $120^{\circ} / \mathrm{s}(0.8,-0.9$ and 1.19, respectively) may be considered large after training. Conclusion: Low-intensity group-based exercise training program may be effective to improve knee isometric peak torque and knee and ankle isokinetic peak torque, power and time acceleration. Trial registration: ACTRN12610000042044.

\section{Resumo}

Objetivos: Verificar se um programa de treinamento de baixa intensidade pode melhorar diferentes variáveis relacionadas a força muscular e controle postural em mulheres idosas da comunidade. Métodos: Estudo clínico randomizado controlado, não cego, em que 37 mulheres foram alocadas de acordo com uma lista de randomização gerada em

\footnotetext{
Departamento de Ciências do Movimento Humano. Universidade Federal de São Paulo. Santos, São Paulo, Brasil.

2 Departamento de Fisioterapia. Universidade Federal de São Carlos. São Carlos, SP, Brasil.

Apoio financeiro: Fundação de Amparo à Pesquisa do Estado de São Paulo (FAPESP: 2006/06656-1 e 2007/06606-7). O conteúdo desta publicação é responsabilidade dos autores e não representa a opinião da fundação financiadora.
}

Key words: Aged. Physical Therapy, Specialty. Muscle Strength. Postural Balance. 
computador, em dois grupos: Controle ( $\mathrm{n}=18$; idade média 68,9(5,7)) e Exercício (n=19; idade média $67,8(4,9))$. As principais avaliações foram controle postural na postura estática e pico de torque isométrico e pico de torque, potência e aceleração isocinética de joelhos e tornozelos. O grupo Exercício realizou um treinamento em grupo duas vezes por semana, por 12 semanas. Cada sessão de treinamento consistiu de exercícios de alongamento, fortalecimento dos músculos do joelho e tornozelo e treino de equilíbrio. O grupo Controle não realizou treinamento. Resultados: $O$ grupo Controle não apresentou diferenças significativas para as variáveis analisadas. O tamanho do efeito depois de 12 semanas de treinamento para o pico de torque e potência para os flexores de joelho do membro inferior não dominante a $60^{\circ} / \mathrm{s}(0,85$ e 0,8 , respectivamente), pico de torque e potência para flexores de joelho do membro inferior não dominante e tempo de aceleração para os extensores de joelho do membro inferior não dominante a $120 \%$ s (0,8; -0,9 e 1,19, respectivamente) podem ser considerados grandes. Conclusão: O treinamento de baixa intensidade em grupo pode ser efetivo para melhorar o pico de torque isométrico, pico de torque, potência e tempo de aceleração isocinético. Registro clínico: ACTRN12610000042044.
Palavras-chave: Idoso. Fisioterapia, Especialidade. Força Muscular. Equilíbrio Postural.

\section{INTRODUCTION}

Quality of life does not change with aging but age affects the risk factors for falls (balance, functional mobility, muscle strength, fear of falling). ${ }^{1}$ Strength-generating capacity of muscles is reduced in elderly people, bringing functional consequences on gait and balance. The weaker muscles of an elderly person may be responsible by decreasing physical and functional independence and increasing the risk of falls, therefore the possibility of suffering a fracture. ${ }^{2}$

Isometric torque was lower in older compared with young adults. They required more time to reach target velocities and were less able to attain high velocities. Peak power was lower for elderly compared with young subjects across all velocities. $^{3}$

It is also widely recognized that elderly with postural instability and risk for falls suffer from multi-sensory loss. Women in their 60s and 70s were more unstable than younger women in bilateral stance on a firm surface with closed eyes. This instability was evident from the 50s when a foam surface was introduced and from the $40 \mathrm{~s}$ when single-limb stance was tested with closed eyes. ${ }^{4}$ However, exercise seems to be important in maintaining functional independence among the elderly because it improves muscle strength, health related quality of life, ${ }^{5}$ balance performance ${ }^{6}$ and, consequently, it may decrease the risk of falls and fractures. ${ }^{7}$

Although it has been stated that different exercise programs are effective at improving muscle strength and balance performance, it is not clear if a low intensity exercise program would be effective to improve isometric peak torque, isokinetic peak torque, power and time acceleration and postural control. Then, the purpose of this paper was to determine if a group-based low intensity exercise training program could significantly improve these different variables among community-dwelling elderly women.

\section{MATERIALS AND METHODS}

This study was a non-blinded randomizedcontrolled trial, developed at the Physiotherapy Department, Federal University of São Carlos, between August 2009 and March 2010. The local ethics committee approved the study (report \#059/2008), which is in agreement with the Declaration of Helsinki. All participants signed an informed consent and were instructed about the study protocol. 
Participants and randomization

Sixty-one women presented to answer one first interview that investigated inclusion and exclusion criteria. At this moment, they were asked to bring a doctor report attesting good health conditions to take part in the study.

The study included 60-year-old women and older living at community. According to the Brazilian Elderly Statute, people aged 60 years or more can be considered elderly and their rights are protected by this law. ${ }^{8}$ Women who used some walking aid, those who presented low scores at Mini-Mental State Examination, ${ }^{9,10}$ or presented a medical report of orthopedics, cardiologic, neurologic and vestibular impairments were excluded.

A parallel randomization (1:1) was carried out. The women were allocated according a computer generated randomization list in two groups: Control or Exercise. For the allocation, a research not involved in data collection or analysis developed a randomization schedule and produced 37 consecutively numbered sealed opaque envelopes containing each participant's allocation. Immediately after collection baseline data, the envelopes were opened.

\section{Isometric and isokinetic evaluation}

Isometric and isokinetic evaluation for the ankle plantar flexors and dorsiflexors and knee extensors and flexors were assessed using a BIODEX isokinetic dynamometer. Ankle evaluation was performed with the volunteer seated, belts placed over her thorax and abdomen, knees at 30 degrees. The foot was attached to a footplate and held in a fixed position by a belt. Ankles were considered at neutral (0 degrees) when it was observed 90 degrees between imaginary lines for tibia and metatarsal bones. The position for isometric evaluation was at 5 degrees of plantar flexion. Range of motion for isokinetic evaluation was from 5 degrees of dorsiflexion to 30 degrees of plantar flexion.
Knee evaluation was also performed with the volunteer seated, belts placed over her thorax and abdomen. Knee was considered at neutral (0 degrees) when it was completed extended. They were positioned at 60 degrees for isometric evaluation. Range of motion for isokinetic evaluation was from 20 to 90 degrees of knee flexion.

Before being tested, all volunteers performed three sub-maximal repetitions in order to become familiarized with the equipment. They performed three valid maximal voluntary contractions for each movement, as forcefully as possible during five seconds for isometric evaluation. One-minute interval between the repetitions was maintained. The isometric peak torque was determined as the highest peak torque $(\mathrm{Nm})$.

They performed three movements at 60 and $120 \%$ for knee and three for ankle at $60 \%$ as forcefully as possible. A three-minute interval between the velocities was maintained. The isokinetic peak torque/body weight and average power were taken at BIODEX report. Time acceleration was determined as the lowest time among the three trials through curves analyses by BIODEX software.

Tests were performed bilaterally, always beginning on the right side. However, the results were grouped for dominant or non-dominant side. Every participant answered right limb as dominant side, when they were questioned about the leg used to kick the ball. Torque generating capacity and neural activation were similar in the dominant and non-dominant limb in healthy non specifically trained subjects. ${ }^{11}$

\section{Postural control evaluation}

Postural control studies were carried out assessing the behavior of the body during quiet erect posture by BERTEC Corporation force platform. Based on the signals measured by the force plate, the center of pressure (COP) position 
in the anteroposterior (AP) and mid-lateral (ML) directions were calculated. ${ }^{12}$ In order to examine the performance of the postural control system in an upright position, the participants were asked to maintain an upright stance OE (opened eyes), upright stance CE (closed eyes), right tandem stance and left tandem stance as still as possible for 60 seconds and right one-leg stance and left one-leg stance for 30 seconds, while staring at a $3.0 \mathrm{~cm}$ diameter target placed at eye level and 2.0 meters away. It was used a selfselected pleasant position during upright stance. However, the distance chosen did not go beyond the shoulder's width. ${ }^{12}$ Safety-was guaranteed by a physiotherapist who took place near volunteer. Three trials were performed for every position, and the trial with a smaller statokinesigram area was chosen for analysis.

The frequency of acquisition of the COP signal was $100 \mathrm{~Hz}$. Data acquisition was carried out by a system developed by EMG System do Brazil. Data treatment and computation were carried out by the MATLAB software (Math Works, version 7.1). Data were filtered by Butterworth low-pass filter of $5 \mathrm{~Hz}$.

Interventions

After the baseline assessments, participants started a group-based exercise training program on two days a week for 12 weeks, under the supervision of a physiotherapist. They were divided into four small groups according to their schedule preferences. The absences were replaced in the same week. It was excluded the volunteer who did not completed 22 sessions in 12 weeks. Each training session consisted of 10 minutes of stretching exercises, 20 minutes of ankle and knee muscle strengthening and 20 minutes of balance training. Blood pressure was verified when they arrived to the training.

Static stretching exercises were carried out for the muscles of the neck, back, arms and legs at the beginning of the session and were followed by the resistance training.
Participants performed ankle plantar flexion by lifting the heels while standing on their feet. Initially, during the adaptation period, the individuals performed four sets of ten bilateral plantar flexion lifts. After six weeks, the participants progressed to four sets of twelve lifts. Ankle dorsiflexion was performed with 0.5 or $1 \mathrm{~kg}$ cuff weights that were wrapped around the front parts of the participant's feet. The dorsiflexion was carried out for the full range of ankle motion for two sets of ten repetitions. It was maintained one-minute rest period between sets to minimize fatigue. Knee extension and flexion was carried out for the full range of motion in kinetic opened chain with $0.5,1$ or $2 \mathrm{~kg}$ ankle cuff weights for two sets of 10 repetitions. Knee extension was performed seated in a chair and knee flexion was performed standing erect.

In the first session, everybody began all exercises with ankle cuff weights of $0.5 \mathrm{~kg}$. Every week they were asked if it was easier to carry out the exercises, in order to determine increment loads. It was maintained one-minute rest period between sets.

Balance training followed Silsupadol et al. ${ }^{13}$ suggestions that determined the progression in balance training increasing body movements, manipulation and mental tasks and taking off visual reference, closing the eyes. Primarily, simple tasks in static balance training consisted of standing in one leg, their heels and tiptoes and tandem position with opened eyes. After four weeks they carried out same postures associated to manual or mental tasks or over some foam. After six weeks, they were encouraged to close their eyes.

Dynamic balance training was divided in two parts. In the first moment, they performed lower support base walking. After that, they performed different ludic activities with balls, balloons, obstacles and canes. The participants carried out backward and tandem walking, and walked on their heels and tiptoes through a trajectory of 15 meters. It was developed simple and double-tasks. 
Participants in the Control group did not undergo any training and were instructed to maintain their usual level of physical activity. They were invited to carry out 12 -week training after the second assessment.

\section{Statistical analyses}

All statistical analyses were performed using Statistica software (StatSoft Inc., Tulsa, OK). All data were analyzed by intention-to-treat. Nonparametric tests were performed because some variables did not present normal distribution by the Shapiro-Wilks test. The intragroup analysis was carried out using Wilcoxon nonparametric test. Comparison among groups was made using Mann-Whitney U test and Chi-square test. The level of significance used for all comparisons was $5 \%(\mathrm{p} \leq 0.05)$. Data were expressed as median (interquartile deviation). In order to measure the practical significance of the data, the effect size and the confidence interval were calculated. The effect sizes were considered mild if values were smaller than 0.20 ; moderate if values were between 0.25 and 0.75 ; and large when values were over $0.80 .^{14}$

\section{RESULTS}

Figure 1 shows the formation of the groups since the first interview that evaluated inclusion and exclusion criteria. The women were evaluated only by a non-blinded experienced physical therapist who performed all evaluations of the two groups, at the beginning of the study and after 12-week intervention. Thirty-seven participants were included at the intention-totreat analysis: Control group ( $\mathrm{n}=18$; mean age 68.9 \pm 5.7 ) and Exercise group ( $\mathrm{n}=19$; mean age 67.8 \pm 4.9 ). One woman of the Exercise and eight of the Control group discontinued treatment. 


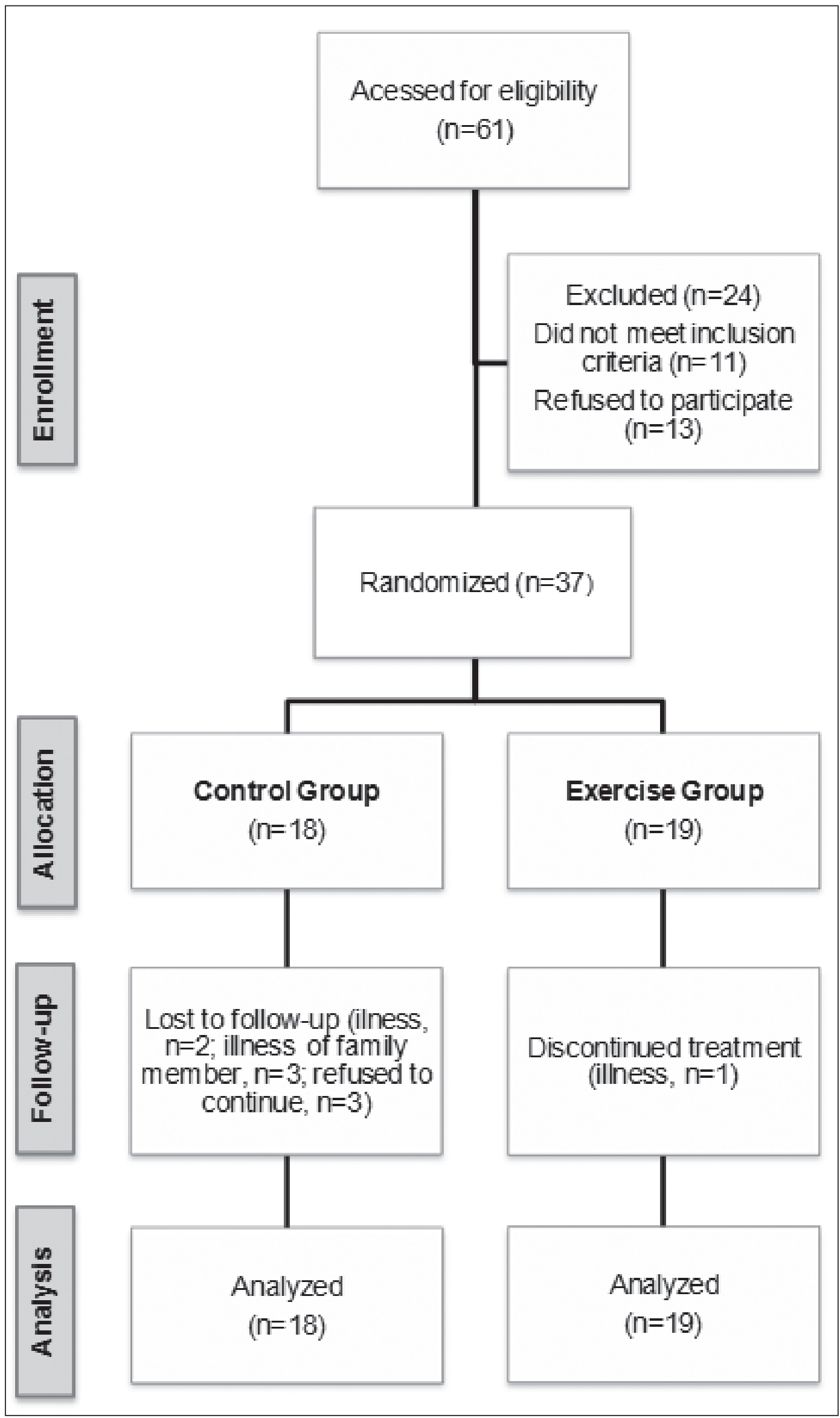

Figure 1 - Participants' enrollment. São Carlos, SP, 2009-2010. 
Table 1 presents isometric peak torque of Control and Exercise groups. Exercise group presented significant increase for knee extensors and flexors isometric peak torque.

Table 1 - Baseline and outcome isometric peak torque for control and exercise groups. São Carlos, SP, 2009-2010.

\begin{tabular}{|c|c|c|c|c|c|c|c|c|c|}
\hline & \multirow[b]{2}{*}{ Muscle group } & \multicolumn{3}{|c|}{ Control Group } & \multicolumn{3}{|c|}{ Exercise Group } & \multirow[b]{2}{*}{$\begin{array}{c}\text { Intergroup } \\
\text { analysis }\end{array}$} & \multirow[b]{2}{*}{$\mathrm{CI}$} \\
\hline & & Baseline & Outcome & $\begin{array}{c}\text { Intragroup } \\
\text { analysis }\end{array}$ & Baseline & Outcome & $\begin{array}{l}\text { Intragroup } \\
\text { analysis }\end{array}$ & & \\
\hline \multirow{4}{*}{ 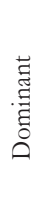 } & Knee Flexors (Nm) & $43.7(13.2)$ & $44.7(8.9)$ & 0.40 & $48.9(9.9)$ & $56.0(11.0)$ & $0.02 *$ & 0.12 & -18.00 to -4.60 \\
\hline & Knee Extensors (Nm) & $79.9(17.6)$ & $94.0(8.7)$ & 0.11 & $105.3(9.8)$ & $110.4(15.8)$ & $0.01 *$ & 0.08 & $-24,98$ to -7.82 \\
\hline & Ankle Dorsiflexors (Nm) & $25.2(5.4)$ & $21.4(4.9)$ & 0.78 & $25.9(3.6)$ & $27.4(2.9)$ & 0.72 & 0.22 & -8.67 to -3.33 \\
\hline & Ankle Plantar Flexors (Nm) & $45.8(6.9)$ & $47.6(14.1)$ & 0.68 & $49.9(13.9)$ & $58.4(13.5)$ & 0.07 & 0.75 & -2.01 to -1.59 \\
\hline \multirow{4}{*}{ 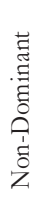 } & Knee Flexors (Nm) & $40.1(13.0)$ & $40.1(9.7)$ & 0.95 & $47.8(5.7)$ & $51.4(7.6)$ & $0.01 *$ & 0.09 & -17.10 to -5.50 \\
\hline & Knee Extensors (Nm) & $80.0(13.1)$ & $81.8(15.1)$ & 0.17 & $94.5(10.7)$ & $96.7(11.3)$ & $0.01 *$ & 0.06 & -23.77 to -6.03 \\
\hline & Ankle Dorsiflexors (Nm) & $23.1(3.8)$ & $22.8(3.2)$ & 0.99 & $26.5(3.6)$ & $26.5(4.3)$ & 0.48 & 0.32 & -45.24 to -40.16 \\
\hline & Ankle Plantar Flexors (Nm) & $54.9(8.6)$ & $49.2(9.1)$ & 0.99 & $51.1(16.4)$ & $59.5(13.4)$ & 0.12 & 0.63 & -17.99 to -2.61 \\
\hline
\end{tabular}

Data are expressed as median (interquartile deviation); *significant; CI:confidence interval.

Table 2 shows isokinetic peak torque, power and time acceleration at $60 \% \mathrm{~s}$ for Control and Exercise groups. Control group did not present any significant differences. Exercise group presented significant increase to peak torque and power for knee flexors; peak torque, power and time acceleration for knee extensors; power and time acceleration for ankle dorsiflexors; and peak torque and power for ankle plantar flexors. Moreover, effect size to peak torque and power for non-dominant knee flexors and peak torque for non-dominant ankle dorsiflexors may be considered large and moderate, respectively. 


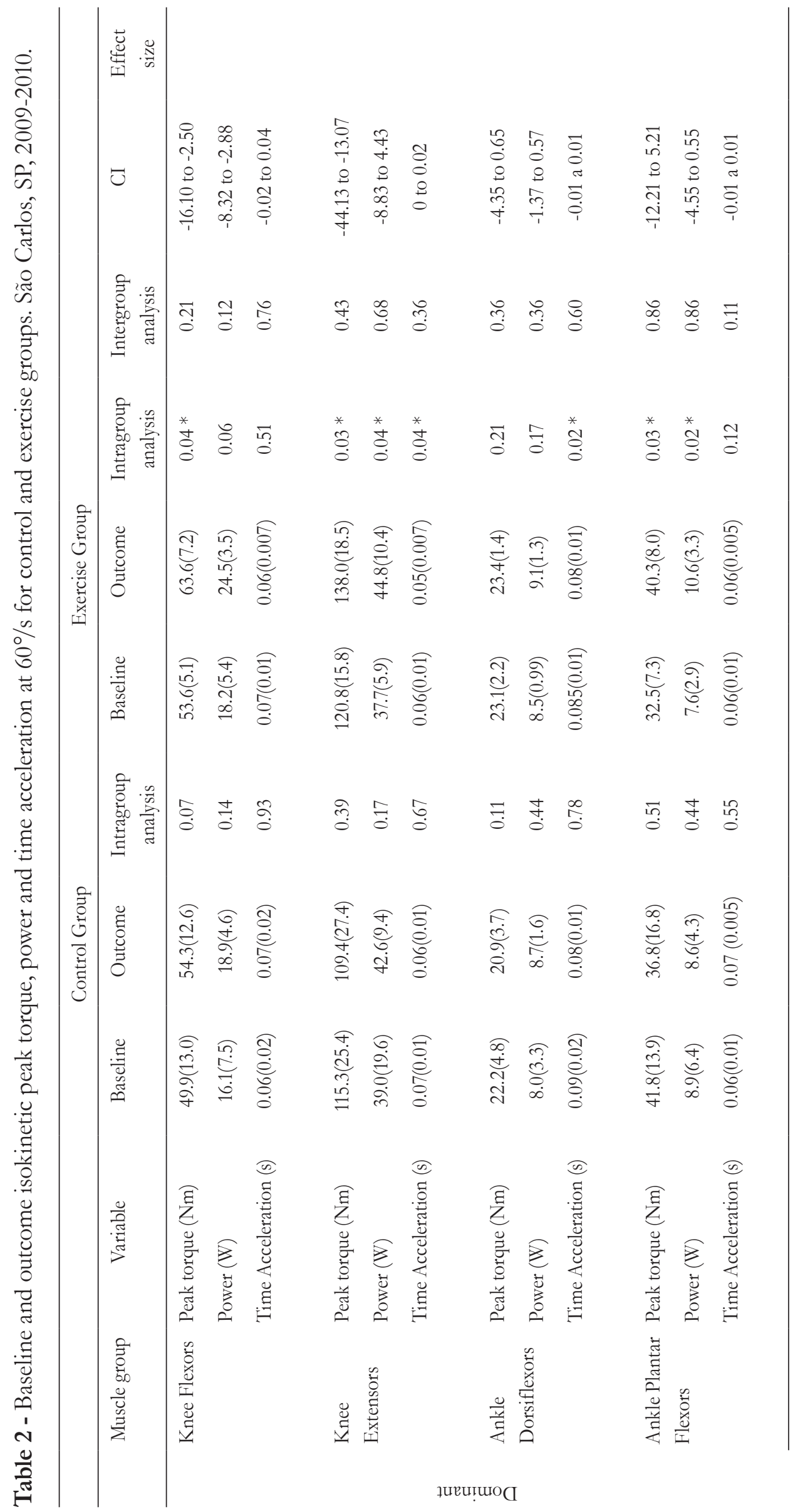




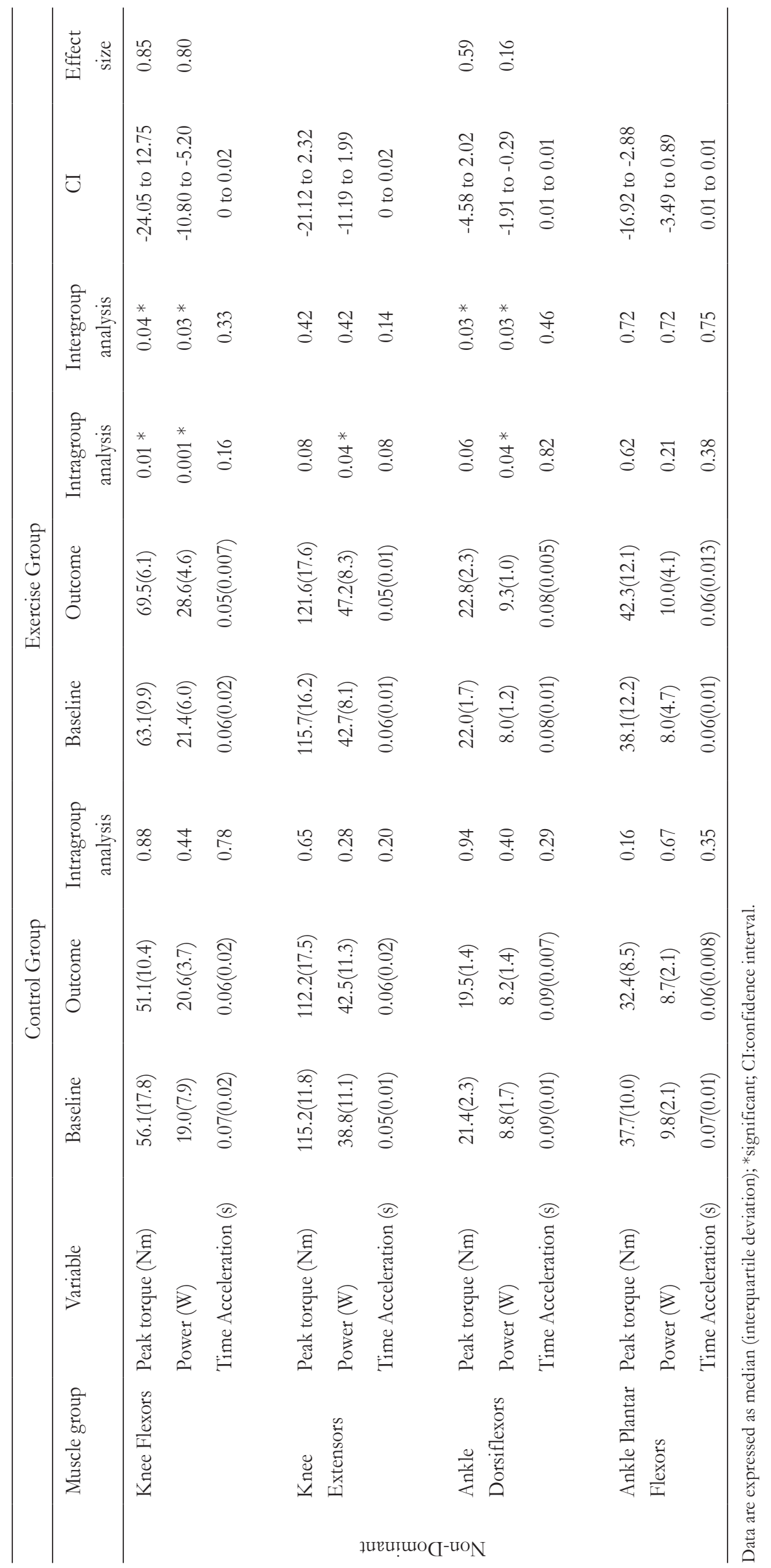


Table 3 shows non-dominant and dominant side isokinetic peak torque, power and time acceleration at $120 \%$ for Control and Exercise groups for knee muscle groups tested. Exercise group presented significant increase to peak torque and power for knee flexors; peak torque, power and time acceleration for knee extensors. Peak torque and power for non-dominant knee flexors and time acceleration for non-dominant knee extensors showed large effect size after 12-week physical therapy.

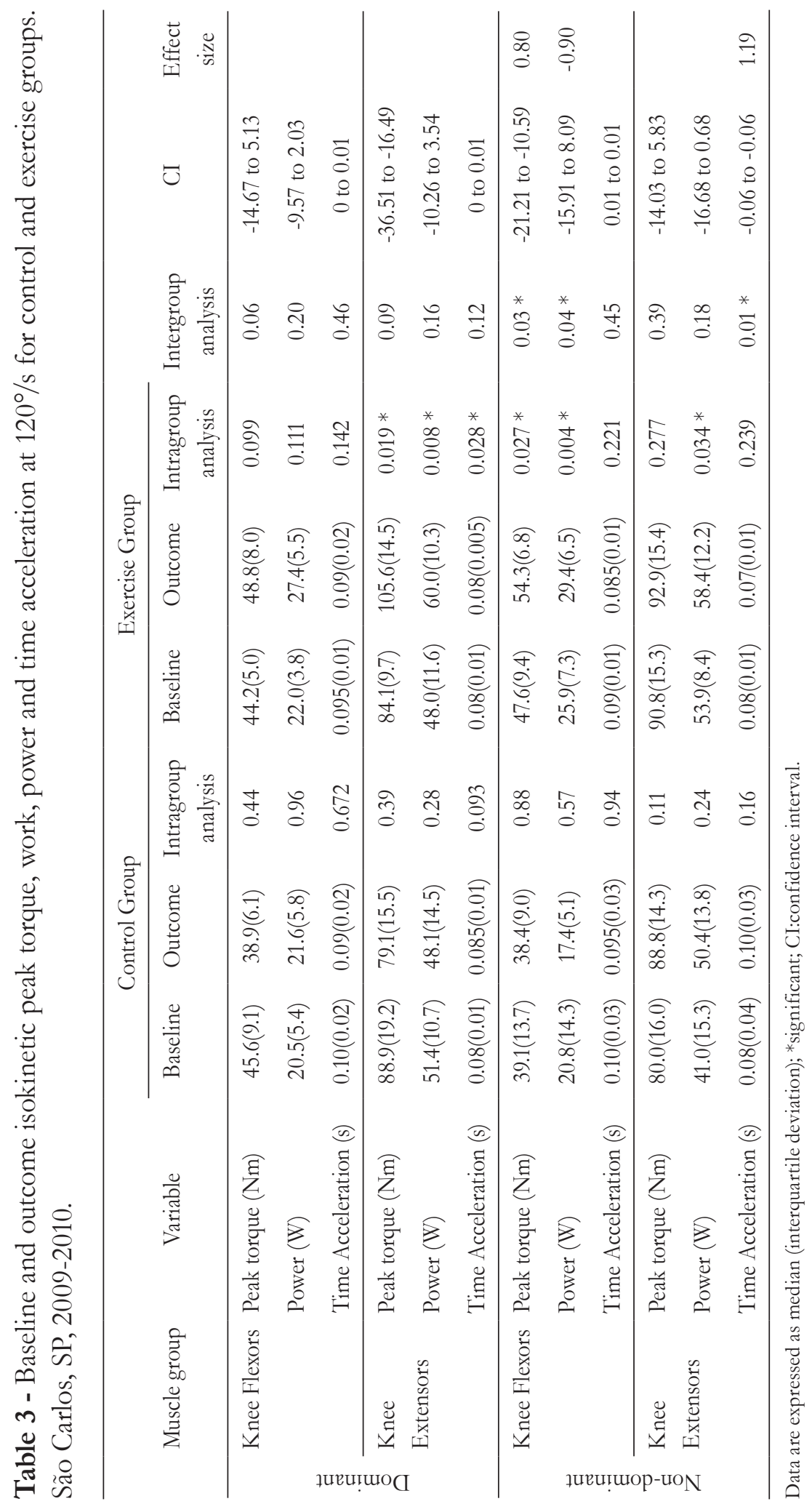


Table 4 shows statokinesigram area at baseline and outcome. Significant worsening to Exercise group for statokinesigram area at left one-leg stance was observed. Control group did not show any significant difference.

Table 4 - Statokinesigram area $\left(\mathrm{cm}^{2}\right)$ for control and exercise groups. São Carlos, SP, 2009-2010.

\begin{tabular}{lccccccccc}
\hline & \multicolumn{3}{c}{ Control Group } & \multicolumn{3}{c}{ Exercise Group } & & \\
\cline { 2 - 6 } \multicolumn{1}{c}{ Posture } & Baseline & Outcome & $\begin{array}{c}\text { Intragroup } \\
\text { analysis }\end{array}$ & Baseline & Outcome & $\begin{array}{c}\text { Intragroup } \\
\text { analysis }\end{array}$ & $\begin{array}{c}\text { Intergroup } \\
\text { analysis }\end{array}$ & CI \\
\hline Upright Stance OE & $1.54(0.46)$ & $1.16(0.25)$ & 0.50 & $0.57(0.44)$ & $0.59(0.39)$ & 0.94 & 0.10 & 0.88 to 1.32 \\
Upright Stance CE & $0.94(0.32)$ & $1.01(0.07)$ & 0.35 & $1.08(0.47)$ & $0.59(0.29)$ & 0.27 & 0.06 & 0.28 to 0.56 \\
Right Tandem Stance & $3.77(0.70)$ & $2.22(1.02)$ & 0.14 & $2.89(1.16)$ & $2.5(0.73)$ & 0.43 & 0.76 & -0.87 to 0.31 \\
Left Tandem Stance & $2.72(1.56)$ & $2.22(0.08)$ & 0.69 & $2.83(0.76)$ & $2.45(0.94)$ & 0.83 & 0.99 & -0.68 to 0.22 \\
Right One-leg Stance & $4.60(1.36)$ & $4.64(1.64)$ & 0.27 & $4.14(1.24)$ & $4.68(1.41)$ & 0.07 & 0.41 & -1.06 to 0.98 \\
Left One-leg Stance & $4.01(0.34)$ & $4.54(1.07)$ & 0.27 & $4.41(1.12)$ & $4.70(2.00)$ & $0.02 *$ & 0.82 & -1.24 to 0.92 \\
\hline
\end{tabular}

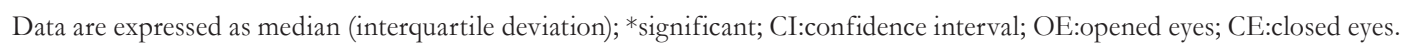

\section{DISCUSSION}

Proposed exercise training did not present enough intensity to improve plantar flexors and dorsiflexors isometric peak torque. Training adaptations are specific to the stimulus applied. The specific physiological adaptations to resistance training are determined by various factors, including muscle actions involved, intensity and volume training. ${ }^{15}$ Furthermore, one can hypothesize that training did not present improvements to ankle muscles because it did not include isometric exercises. Specifically, certain isometric actions have been effective for the selective recruitment of postural, spinalstabilization musculature,${ }^{15}$ which was not the present goal.

However, it was found a significant increase in isometric peak torque in the study by Aveiro et al. ${ }^{16} \mathrm{~A}$ similar 12 -week training program was conducted but it was performed three times a week, what may be a better option to improve ankle isometric peak torque. Moreover, the proposed 6-week low cost, three times a week, strength training by elastic bands of dorsiflexors and plantar flexors in the study by Ribeiro et al. ${ }^{17}$ also improved strength, balance and functional mobility in institutionalized elderly.

Lower isometric peak torque seems to be related to muscle mass loss in elderly people, because isometric is well-correlated to crosssectional muscle. ${ }^{3}$ The large increase in torque that Ferri et al. ${ }^{18}$ found after 16 -week training was partly accounted for a significant increase in the cross-sectional area of the plantar flexors and knee extensors. A decrease in antagonist muscle coactivation, an improved co-ordination and modifications intrinsic to the single fibers are proposed as possible mechanisms responsible for the discrepancy between the increase in muscle size and that of muscle strength. ${ }^{18}$ Moreover, training caused an upward displacement of the torque-velocity relationship. Power increase was also significant at all tested velocities. The data obtained showed that this increase in power is mostly a result of an increase in strength, which seems mostly accounted for muscular factors, and possibly, by an increased co-ordination. ${ }^{18}$

Marsh et al. ${ }^{19}$ found that in older adults with compromised function, power and strength training, at knee extension and leg-press, leads to 
similar increases to strength and larger increases to power as compared with strength training to leg-press 1RM. Strength and high-velocity resistance training in healthy, well-functioning older adults significantly and similarly improved muscle power and muscle strength. In addition, changes in muscle function may be accompanied by the enhancement of selected functional tasks. ${ }^{20}$

Findings by De Vos et al. ${ }^{21}$ showed that improvements in peak power after explosive resistance training using loads of $20 \%, 50 \%$, or $80 \%$ of $1 \mathrm{RM}$ occur primarily as a result of improved force production. There might be a trend for force to contribute less (and velocity more) to the improvements in peak power with low-intensity than with high-intensity training.

The fact that muscle power increases seems of particular functional significance, as most daily activities involve the displacement of the body, or segments of it over time, and lower explosive power may be predictive of future falls in older women who live independently. ${ }^{22}$

Improvements in leg-muscle strength measured for knee flexors and extensors at isokinetic dynamometer were only associated with the resistance training program in the study conducted by Bird et al. ${ }^{6}$ It comprised exercises focusing on major muscle groups and used free weights, loaded exercise machines, and body weight for resistance. ${ }^{6}$ It seems that high-intensity training best improves muscle strength and endurance whereas low-intensity training best improves balance performance, and relative improvements in peak power might be achieved equally with low-, moderate-, or high-intensity training. ${ }^{21}$

The acceleration period that occurs during isokinetic tests may provide valuable information regarding neuromuscular readiness to produce maximal contraction. Additional forces such as higher muscle strength contraction significantly reduced the acceleration time and allowed the limbs to reach the constant velocity phase more rapidly. The ability to produce force quickly is extremely important in most functional and sporting activities. ${ }^{23}$
Lanza et al. ${ }^{3}$ found that older adults showed significant increase in the time required to attain target velocity in dorsiflexors. This age-related slowing of contraction velocity may be due to a number of changes in muscle morphology and function with age, including a selective loss of type II muscle fiber area, increased proportion of type I fibers, and an impaired ability to generate high motor unit discharge rates.

On the other hand, it was just observed some worsening to sway area at left one-leg stance in the Exercise group. These results may show that training was not appropriate and/or did not present enough intensity and frequency to improve postural control at upright and tandem stance. Sihnoven et $\mathrm{al}^{24}$ had just observed improvement in the more demanding standing positions. The velocity moment, that combines the aspects of sway velocity and the amplitude of sway, improved in the training group in the more demanding standing positions. This may indicate that tests posing no challenge to the postural control may not be sensitive enough for change. ${ }^{24}$

Bird et al. ${ }^{6}$ found a significant improvement to mean sway velocity at upright stance with eyes opened and closed through resistance training among elderly; however, it was carried out for 16 weeks, three times a week, so it presented larger frequency. It was also observed by Bird et al. ${ }^{6}$ that improvements in balance through resistance training will be valuable to older adults wishing to improve their stability and potentially reduce falls. Older adults showed larger areas of sway regardless of condition, when compared with younger adults. ${ }^{25}$

Probably, thirty seconds were not the best choice for this kind of assessments among elderly. Each balance task was held for three 10-second trials or less if the subject could not hold the unsupported position, or until foot-down for the one-leg stance tests in the study by Choy et al. ${ }^{4}$, because many 60- and 70-year-old people have difficulty completing test conditions when thirty consecutive seconds are used in trials. ${ }^{4}$

There were other limitations in this study. The main limitation was that the therapist who 
carried out the evaluation and treatment was not blinded and this could have influenced the results, consciously or not. It cannot also be ignored that a larger sample size could have altered some of the results of the study. Therefore further research is required before definite conclusions can be drawn. However, despite the small sample size, the calculation of effect size showed that the treatment had large effect on some clinical variables.

All subjects were instructed to maintain their usual level of physical activity although this variable was not controlled. There is no guarantee that the Control group did not perform significant training during this period and this might have influenced the results. However, the volunteers performed three submaximal repetitions with a short period to familiarize with the equipment, what is a better number of repetitions during the test and number of sessions for adaptation.

Peak torque, peak torque adjusted for body weight, total work and coefficient of variation may improve in the second knee extension flexion isokinetic testing of postmenopausal women representing motor learning effects on clinical isokinetic evaluation. ${ }^{26}$ Moreover, since five repetitions at $60 \%$ s with peak torque as the main outcome is the overall most established protocol for isokinetic assessments of knee extension

\section{REFERENCES}

1. Ozcan A, Donat H, Gelecek N, Ozdirenc M, Karadibak D. The relationship between risk factors for falling and the quality of life in older adults. BMC Public Health 2005;5:90.

2. Williams GN, Higgins MJ, Lewek MD. Aging skeletal muscle: physiologic changes and the effects of training. Phys Ther 2002;82(1):62-8

3. Lanza IR, Towse TF, Caldwell GE, Wigmore DM, Kent-Braun JA. Effects of age on human muscle torque, velocity, and power in two muscle groups. J Appl Physiol 2003;95(6):2361-9.

4. Choy NL, Brauer S, Nitz J. Changes in postural stability in women aged 20 to 80 years. J Gerontol A Biol Sci Med Sci 2003;58(6):525-30. and flexion, Eitzen et al. ${ }^{27}$ also suggested this protocol when testing postmenopausal women.

Furthermore, some participants did not achieve the $120 \%$ s velocity for ankle observed through curves analyses by BIODEX software at pilot assessments. This was observed in the study by Lanza et al., ${ }^{3}$ where older subjects began to fail to reach target velocities higher than $120 \%$ s. Then, it was not possible to include this assessment to ankle muscles, what limited some conclusions.

\section{CONCLUSION}

The proposed program may be effective to improve knee isometric peak torque and knee and ankle isokinetic peak torque, power and time acceleration, considering that they are important for the functional activities, including those involving mobility and balance; however, postural control may not be sensitive enough for change.

Since it is a low-cost effective program, it can be applied in community-dwelling elderly women, especially to prevent falls. It can be valuable for the policies and programs for elderly health care, considering that fall-related injuries are a significant government cost during hospitalization, which becomes even greater when the elderly feel their autonomy and independence are being reduced.

5. Eyigor S, Karapolat H, Durmaz B. Effects of a groupbased exercise program on the physical performance, muscle strength and quality of life in older women. Arch Gerontol Geriatr 2007;45(3):259-71.

6. Bird ML, Hill K, Ball M, Williams AD. Effects of resistance- and flexibility-exercise interventions on balance and related measures in older adults. J Aging Phys Act 2009;17(4):444-54.

7. Steadman J, Donaldson N, Kalra L. A randomized controlled trial of an enhanced balance training program to improve mobility and reduce falls in elderly patients. J Am Geriatr Soc 2003;51(6):847-52.

8. Brasil. Ministério da Saúde. Estatuto do Idoso. Brasília: Editora MS; 2003 [acesso em 2005 Dec 27]. Disponível em: http://www.saude.gov.br/. 
9. Folstein MF, Folstein SE, McHugh PR. Mini-mental state: a pratical method for grading the cognitive state of patients for the clinician. J Psychiatr Res 1975;12(3):189-98.

10. Bertolucci PH, Brucki SM, Campacci SR, Juliano Y. The Mini-mental State Examination in a general population: impacto f educational status. Arq Neuropsiquiatr 1994;52(1):1-7.

11. Ruiter JC, Korte A, Schreven S, Haan A. Leg dominancy in relation to fast isometric torque production and squat jump height. Eur J Appl Physiol 2010;108(2):247-55.

12. Duarte M, Freitas SM. Revision of posturography based on force plate for balance evaluation. Braz J Phys Ther 2010;14(3):183-92.

13. Silsupadol P, Siu KC, Shumway-Cook A, Woollacott $\mathrm{MH}$. Training of balance under single- and dual-task conditions in older adults with balance impairment. Phys Ther 2006;86(2):269-81.

14. Urdan TC. Statistics in Plain English. 2nd ed. Mahwah, New Jersey: Lawrence Erlbaum Associates; 2005. 184 p.

15. American College of Sports Medicine. American College of Sports Medicine position stand. Progression models in resistance training for healthy adults. Med Sci Sports Exerc 2009;41(3):687-708.

16. Aveiro MC, Granito RN, Navega MT, Driusso P, Oishi J. Influence of a physical training program on muscle strength, balance and gait velocity among women with osteoporosis. Braz J Phys Ther 2006;10(4):441-8.

17. Ribeiro F, Teixeira F, Brochado G, Oliveira J. Impact of low cost strength training of dorsi- and plantar flexors on balance and functional mobility in institucionalized elderly people. Geriatr Gerontol Int 2009;9(1):75-80.

18. Ferri A, Scaglioni G, Pousson M, Capodaglio P, Van Hoecke J, Narici MV. Strength and power changes of the human plantar flexors and knee extensors in response to resistance training in old age. Acta Physiol Scand 2003;177(1):69-78.

19. Marsh AP, Miller ME, Rejeski WJ, Hutton SL, Kritchevsky SB. Lower extremity muscle function after strength or power training in older adults. J Aging Phys Act 2009;17(4):416-43.

20. Henwood TR, Riek S, Taaffe DR. Strength versus muscle power-specific resistance training in community-dwelling older adults. J Gerontol A Biol Sci Med Sci 2008;63(1):83-91.

21. de Vos NJ, Singh NA, Ross DA, Stavrinos TM, Orr R, Fiatarone Singh MA. Effect of Power-training intensity on the contribution of force and velocity to peak power in older adults. J Aging Phys Act 2008;16(4):393-407.

22. Skelton DA, Kennedy J, Rutherford OM. Explosive power and asymmetry in leg muscle function in frequent fallers and non-fallers aged over 65. Age Ageing 2002;31(2):119-25.

23. Chen WL, Su FC, Chou YL. Significance of acceleration period in a dynamic strength testing study. J Orthop Sports Phys Ther 1994;19(6):324-30.

24. Sihnoven SE, Sipilä S, Era PA. Changes in postural balance in frail elderly women during a 4-week visual feedback training: a randomized controlled trial. Gerontology 2004;50(2):87-95.

25. Hageman PA, Leibowitz JM, Blanke D. Age and gender effects on postural control measures. Arch Phys Med Rehabil 1995;76(10):961-5.

26. Brech GC, Ciolac EG, Secchi LL, Alonso AC, Greve JM. The effects of motor learning on clinical isokinetic performance of postmenopausal women. Maturitas 2011;70(4):379-82.

27. Eitzen I, Hakestad KA, Risberg MA. Inter- and Intrarater reliability of isokinetic thigh muscle strength tests in postmenopausal women with osteopenia. Arch Phys Med Rehabil 2012;93(3):420-7. 